\title{
Prevention of Hepatocellular Carcinoma
}

\author{
Kerstin Schütte $^{b} \quad$ Fathi Balbisi $^{a} \quad$ Peter Malfertheiner ${ }^{a}$ \\ ${ }^{a}$ Department of Gastroenterology, Hepatology and Infectious Diseases, Otto von Guericke \\ University of Magdeburg, Magdeburg, and ${ }^{b}$ Department of Internal Medicine and \\ Gastroenterology, Niels-Stensen-Kliniken, Marienhospital Osnabrück, Osnabrück, Germany
}

\section{Key Words}

Hepatitis B virus - Hepatitis C virus · Hepatocellular carcinoma - Nonalcoholic fatty liver disease $\cdot$ Nonalcoholic steatohepatitis $\cdot$ Prevention

\begin{abstract}
The epidemiology of hepatocellular carcinoma (HCC) has significantly changed throughout the past decade and will continue to do so in the future as a consequence of effective primary prevention and treatment of virus-related liver diseases. However, other risk factors for HCC are constantly on the rise, including alcoholic liver disease and nonalcoholic fatty liver disease. The knowledge on these and further risk factors associated with an increased risk of HCC provide the opportunity and chance for the development and implementation of successful preventive strategies to decrease the worldwide burden of HCC. This mini-review gives a short overview on current strategies in primary, secondary, and tertiary prevention of HCC.
\end{abstract}

\section{Introduction}

The incidence of hepatocellular carcinoma (HCC) is still on the rise with 782,000 new cancer cases having occurred worldwide in 2012 [1]. More than $80 \%$ of the liver cancer cases were diagnosed in less developed regions of the world. Liver cancer is still the second most common cause of death from cancer worldwide, and is estimated to be responsible for nearly 746,000 deaths in 2012. Chronic liver diseases are the most significant risk factor for HCC development. The incidence varies among geographical regions mostly and is influenced by the distribution of the major etiological factors [2]. The majority of cases develops in the setting of chronic liver inflammation that progressed to liver fibrosis or cirrhosis which is the 
major risk factor in 70-90\% of patients [2]. About $75 \%$ of cases are related to chronic virusinduced hepatitis, with hepatitis B virus (HBV) infection being the predominant risk factor worldwide. Other leading risk factors for HCC include, amongst others, hepatitis C virus (HCV) infection, contamination of food with aflatoxin, alcohol-induced liver disease (ALD), and nonalcoholic steatohepatitis (NASH). The interventions on the prevalence of some of these risk factors, including HBV immunization programs, successful treatments of HCV infection, and reduction of aflatoxin food contamination, have already resulted in significant changes in the epidemiology of HCC. Notably, there is a decrease of infection-related cases but an increase in cases related to other risk factors, with NASH being the predominant factor [3]. For younger patients, HCC results in the loss of a considerable number of years-of-life with an estimated lifespan loss of 19.1 years shown in a recent study [4]. The knowledge about risk factors for HCC provides the opportunity and chance for the development and implementation of preventative strategies aiming at an efficient and effective prevention of HCC to decrease the worldwide burden of the disease [5]. Primary prevention focuses on risk factors for HCC and their treatment at an early stage, secondary prevention concentrates on the treatment of underlying liver diseases in patients with HCC aiming at a prevention of disease progression, and tertiary prevention aims at a reduction of recurrence after successful curative treatment of HCC. This review gives a short overview on current strategies in primary, secondary, and tertiary prevention of HCC.

\section{Strategies with a Focus on HBV-Related HCC}

Worldwide more than 50\% of HCC cases are attributed to chronic HBV infection [6]. A recent systematic review and meta-analysis has revealed a strong correlation of HCC risk in patients with untreated HBV infection with stage of liver disease and age. The incidence rates ranged from 0.07 to 0.42 per 100 person-years in asymptomatic carriers with regional differences between Europe, North America, and Asia, from 0.03 to 0.17 in inactive carriers, from 0.12 to 0.49 in patients with chronic hepatitis, and from 2.03 to 3.37 in patients with decompensated liver cirrhosis [7].

The serum level of HBV DNA is a significant cofactor for the risk of HCC and such are other clinical, viral, demographical, and environmental factors [8].

To prevent the complications of chronic HBV infection, the World Health Organization (WHO) [9] recommends to include hepatitis B vaccination in routine immunization services in all countries. A universal hepatitis B vaccination program has been implemented in 47 of 53 European countries. The first country to routinely vaccinate newborns against HBV was Taiwan who introduced this in 1984. Since then, the rate of HBV infection carriers was significantly reduced, especially in the younger population, which was associated with a significant incidence reduction of HCC in the young by $75 \%[10,11]$. A drop in the age-standardized incidence rate for HCC after the implementation of vaccination programs has also been demonstrated in other countries, including Singapore, China, and Thailand [12].

Another essential strategy to prevent HCC related to chronic viral hepatitis is testing blood products for HBV and HCV as well as adoption of universal precautions to avoid transmission of blood-borne viruses in healthcare settings [13].

Besides primary prevention of HBV infection, effective antiviral treatment of HBV reduces the risk of HCC. Long-term application of nucleos(t)ide analogs (NA) can result in the improvement of necroinflammation and reversal of fibrosis or even cirrhosis [14]. Most data on the effect of HBV treatment on the risk of HCC comes from studies on interferon therapies and lamivudine $[15,16]$. Currently, there is no evidence from prospective randomized controlled trials that show a superiority in terms of HCC prevention with the newer NAs, ente- 
cavir and tenofovir disoproxil fumarate, that have a high antiviral potency as well as a high barrier to drug resistance [12]. Risk scores based on demographic (age, sex), clinical (cirrhosis, ALT, albumin, and bilirubin) and virologic characteristics (HBeAg status, HBV DNA) have been developed and predict HCC in Asian chronic hepatitis B patients treated with entecavir, but to a lesser extend in Caucasians $[17,18]$. Because intrahepatic cccDNA cannot be eliminated so far, even the new potent drugs are not able to fully eliminate the risk of HCC in chronic hepatitis B-infected patients [19]. Thus, careful surveillance remains mandatory for these patients, particularly in patients with cirrhosis.

In patients that have been diagnosed with HCC related to HBV infection, treatment of HBV in addition to HCC has been demonstrated to significantly improve survival. After curative treatment for HBV-related HCC, controlling viral status seems to be important to prevent HCC recurrence and improve survival. Therapy with interferon and NAs may be useful for preventing HCC recurrence and improving overall survival in patients who have undergone curative resection for HBV-related HCC [20, 21].

\section{Prevention of HCV-Related HCC}

HCV is a parenterally transmitted virus. The introduction of anti-HCV testing resulted in a substantial reduction of hepatitis $C$ after transfusion [13]. Nowadays, intravenous drug abuse is the primary cause of HCV transmission. Education programs, needle and syringe exchange programs, safe injecting rooms, and special programs are therefore important measures in the primary prevention of HCV-related HCC but have not satisfactorily shown to be effective. Sexual transmission can be prevented by safe-sex strategies. The outstanding development of new effective therapies against HCV infection will likely have an important impact on HCV-related HCC. Successful treatment of the infection slows liver disease progression and may reduce the risk of cirrhosis and HCC. A meta-analysis of observational studies revealed that sustained virological response is associated with a significantly reduced risk for HCC [relative risk for all persons, 0.24 (95\% CI 0.18-0.31)] [5, 22]. With the new interferon-free therapies of HCV infection applying new direct-acting antiviral agents, sustained virological response rates of up to $100 \%$ after 12 weeks have been reported in clinical trials irrespective of the genotype and have already been confirmed in real-world settings [23, 24-26]. Nevertheless, also after an effective HCV infection treatment, HCC still develops in some of these patients, especially in the setting of cirrhosis, although it will occur with less likelihood (HR 0.25 in prospective studies) [27]. It is still not clear, however, how successfully anti-HCV therapy will impact on liver fibrosis in the long term and which parameters are useful to identify patients at risk to develop HCC even after HCV clearance [28, 29].

Remarkably, fewer than $20 \%$ of infected patients receive treatment of HCV infection in the US and Europe, mostly because patients are not aware of the infection [5]. Hence, this rather low level of treatment penetrance will result in a moderate reduction of HCC incidence attributable to HCV infection in the near future. It cannot be decided yet, if and at what time point patients healed from HCV infection can be dismissed from HCC surveillance and if HCV treatment still has a preventive effect on hepatocarcinogenesis in the stage of advanced liver disease [30]. Several studies have also demonstrated a beneficial effect in term of preventing HCC recurrence in patients after curative resection of HCC in HCV-related liver disease by eradication of HCV. Most of these studies applied interferon [31]. In contrast, it has been demonstrated in a small study that HCV eradication with antiviral agents in patients who have undergone curative treatment of HCC in advance is associated with high recurrence rates of HCC. It is hypothesized that disruption of immune surveillance may facilitate the emergence of metastatic clones [32]. 


\section{Chronic ALD and HCC}

In the Western world, chronic ALD has become one of the leading risk factors for HCC with the special challenge that these patients are frequently missed by surveillance programs, resulting in advanced tumor stages at the time of diagnosis [33-35]. Early diagnosis of ALD is important to encourage alcohol abstinence, minimize the progression of liver fibrosis, and manage cirrhosis-related complications including HCC [36]. The annual HCC rate among patients with Child-Pugh Class A or B alcoholic cirrhosis is about 2.5\% [37]. Curing ALD by total abstinence is a challenge. However, a meta-analysis indicates that the risk of hepatic cancer actually decreases after giving up alcohol by 6-7\% a year. An estimated period of 23 years is necessary after giving up drinking, i.e. a correspondingly high $95 \%$ CI period of 14-70 years, in order that the risk of hepatic cancer becomes the same as that of teetotalers $[38,39]$.

\section{Options in Prevention of NASH-Associated HCC and HCC Associated with Metabolic Risk Factors}

The pathogenesis of HCC in NAFLD is multifactorial involving obesity-mediated mechanisms leading to low-grade chronic inflammation. HCC risk is increased in obesity and diabetes, which constitute two major risk factors for NAFLD [40]. Even in the absence of cirrhosis, a progression from NASH to HCC has been reported [41, 42]. Weight reduction, e.g. by bariatric surgery, has been demonstrated to improve liver fibrosis [43, 44]. Physical activity can improve hepatic steatosis and metabolic indices even without weight loss [44, 45]. Whether this already lowers the risk for HCC has not been sufficiently addressed in clinical studies so far. Targeting the obesity-related inflammation and improvement of insulin resistance with the aim of chemoprevention of hepatocarcinogenesis is in the focus of current research $[46,47]$. In diabetics, the use of metformin is associated with a reduced incidence of HCC [48-50], with an odds ratio of 0.30 in a meta-analysis [51]. In addition, the intake of statins reduces the risk of HCC (OR 0.63) in observational studies [52, 53]. There is evidence from early studies pointing at the possibility that treatment with a caspase inhibitor might improve liver histology in NASH $[54,55]$. Obeticholic acid, a potent activator of the farnesoid X nuclear receptor, improved the histological features of NASH, but its long-term benefits and safety need further evaluation as well as its preventive effects on hepatocarcinogenesis [56].

\section{Other Causes of Chronic Liver Disease}

Hereditary hemochromatosis is a frequent autosomal recessive disorder with frequencies of homozygosity for the most common mutation C282Y reaching up to 1 in 200 and with a disease penetrance ranging from 10 to $60 \%$ [57]. In these patients, the presence of cirrhosis is not a prerequisite for HCC development, but early diagnosis and sufficient treatment of iron overload reduces the risk for HCC in these patients [58].

In less developed countries, aflatoxin exposition significantly contributes to the burden of HCC. Preventive measures include public health strategies aiming at a reduction of aflatoxin exposure, including agricultural strategies, methods to reduce humidity and fungal growth, and pharmacological interventions to attenuate the toxicological consequences of unavoidable aflatoxin exposure [57, 59]. 


\section{Conclusion}

The epidemiology of HCC has significantly changed throughout the past decade and will continue to change in the future as a consequence of effective primary prevention and treatment of virus-related liver diseases. However, other risk factors for HCC are constantly on the rise, including ALD and NAFLD. It will be one of the major challenges to improve awareness for patients at risk for HCC development even in the absence of cirrhosis and develop efficient and effective monitoring and intervention strategies to prevent HCC.

\section{References}

1 International Agency for Research on Cancer. Globocan 2012: Liver Cancer Fact Sheet. Lyon, IARC.

-2 Schütte K, Bornschein J, Malfertheiner P: Hepatocellular carcinoma -epidemiological trends and risk factors. Dig Dis 2009;27:80-92.

-3 Goh GB, Chang P, Tan C: Changing epidemiology of hepatocellular carcinoma in Asia. Best Pract Res Clin Gastroenterol 2015;29:919-928.

4 Cucchetti A, Trevisani F, Bucci L, Ravaioli M, Farinati F, Giannini EG, Ciccarese F, Piscaglia F, Rapaccini GL, Di Marco M, Caturelli E, Zoli M, Borzio F, Sacco R, Maida M, Felder M, Morisco F, Gasbarrini A, Gemini S, Foschi FG, Missale G, Masotto A, Affronti A, Bernardi M, Pinna AD: Years of life that could be saved from prevention of hepatocellular carcinoma. Aliment Pharmacol Ther 2016;43:814-824.

-5 Singal AG, El-Serag HB: Hepatocellular carcinoma from epidemiology to prevention: translating knowledge into practice. Clin Gastroenterol Hepatol 2015;13:2140-2151.

-6 European Association for the Study of the Liver; European Organisation for Research and Treatment of Cancer: EASL-EORTC clinical practice guidelines: management of hepatocellular carcinoma. J Hepatol 2012; 56:908-943.

7 Raffetti E, Fattovich G, Donato F: Incidence of hepatocellular carcinoma in untreated subjects with chronic hepatitis B: a systematic review and meta-analysis. Liver Int DOI: 10.1111/liv13142, Epub ahead of print.

8 El-Serag HB: Epidemiology of viral hepatitis and hepatocellular carcinoma. Gastroenterology 2012;142:12641273.e1.

-9 Lernout T, Hendrickx G, Vorsters A, Mosina L, Emiroglu N, van Damme P: A cohesive European policy for hepatitis B vaccination, are we there yet? Clin Microbiol Infect 2014;20(suppl 5):19-24.

10 Chang MH: Hepatitis B virus and cancer prevention. Recent Results Cancer Res 2011;188:75-84.

-11 Chang MH, Chen CJ, Lai MS, Hsu HM, Wu TC, Kong MS, Liang DC, Shau WY, Chen DS: Universal hepatitis B vaccination in Taiwan and the incidence of hepatocellular carcinoma in children. Taiwan Childhood Hepatoma Study Group. N Eng J Med 1997;336:1855-1859.

$\checkmark 12$ Kao J: Hepatitis B vaccination and prevention of hepatocellular carcinoma. Best Pract Res Clin Gastroenterol 2015;29:907-917.

13 Asia-Pacific Working Party on Prevention of Hepatocellular Carcinoma: Prevention of hepatocellular carcinoma in the Asia-Pacific region: consensus statements. J Gastroenterol Hepatol 2010;25:657-663.

14 Su T, Kao J: Improving clinical outcomes of chronic hepatitis B virus infection. Expert Rev Gastroenterol Hepatol 2015;9:141-154.

15 Liaw YF: Does chemotherapy prevent HBV-related hepatocellular carcinoma? Pros. Dig Liver Dis 2010; 42(suppl 3):S293-S297.

-16 Liaw YF, Sung JJY, Chow WC, Farrell G, Lee C, Yuen H, Tanwandee T, Tao Q, Shue K, Keene ON, Dixon JS, Gray DF, Sabbat J: Lamivudine for patients with chronic hepatitis B and advanced liver disease. N Engl J Med 2004; 351:1521-1531.

$>17$ Wong GL, Chan HL, Chan H, Tse PC, Tse Y, Mak CW, Lee SK, Ip ZM, Lam AT, Iu HW, Leung JM, Wong VW: Accuracy of risk scores for patients with chronic hepatitis B receiving entecavir treatment. Gastroenterology 2013;144:933-944.

-18 Yang H, Yuen M, Chan HL, Han K, Chen P, Kim D, Ahn S, Chen C, Wong VW, Seto W: Risk estimation for hepatocellular carcinoma in chronic hepatitis B (REACH-B): development and validation of a predictive score. Lancet Oncol 2011;12:568-574.

19 Arends P, Sonneveld MJ, Zoutendijk R, Carey I, Brown A, Fasano M, Mutimer D, Deterding K, Reijnders JGP, Oo Y, Petersen J, van Bömmel F, de Knegt RJ, Santantonio T, Berg T, Welzel TM, Wedemeyer H, Buti M, Pradat P, Zoulim F, Hansen B, Janssen HLA: Entecavir treatment does not eliminate the risk of hepatocellular carcinoma in chronic hepatitis B: limited role for risk scores in Caucasians. Gut 2015;64:1289-1295.

-20 Zhang P, Yang Y, Wen F, Wheeler J, Fu P, Li Q: Cost-effectiveness analysis of antiviral therapy in patients with advanced hepatitis B virus-related hepatocellular carcinoma treated with sorafenib. J Gastroenterol Hepatol 2016 DOI: 10.1111/jgh 13425, Epub ahead of print. 
21 Kubo S, Takemura S, Tanaka S, Shinkawa H, Nishioka T, Nozawa A, Kinoshita M, Hamano G, Ito T, Urata Y: Management of hepatitis B virus infection during treatment for hepatitis B virus-related hepatocellular carcinoma. World J Gastroenterol 2015;21:8249-8255.

22 Morgan RL, Baack B, Smith BD, Yartel A, Pitasi M, Falck-Ytter Y: Eradication of hepatitis C virus infection and the development of hepatocellular carcinoma: a meta-analysis of observational studies. Ann Int Med 2013; 158:329-337.

23 Feld JJ, Jacobson IM, Hézode C, Asselah T, Ruane PJ, Gruener N, Abergel A, Mangia A, Lai C, Chan HLY, Mazzotta F, Moreno C, Yoshida E, Shafran SD, Towner WJ, Tran TT, McNally J, Osinusi A, Svarovskaia E, Zhu Y, Brainard DM, McHutchison JG, Agarwal K, Zeuzem S: Sofosbuvir and velpatasvir for HCV genotype 1, 2, 4, 5, and 6 infection. New Engl J Med 2015;373:2599-2607.

24 Walker DR, Pedrosa MC, Manthena SR, Patel N, Marx SE: Early view of the effectiveness of new direct-acting antiviral (DAA) regimens in patients with hepatitis C virus (HCV). Adv Ther 2015;32:1117-1127.

25 Zeuzem S, Ghalib R, Reddy KR, Pockros PJ, Ben Ari Z, Zhao Y, Brown DD, Wan S, DiNubile MJ, Nguyen B, Robertson MN, Wahl J, Barr E, Butterton JR: Grazoprevir-elbasvir combination therapy for treatment-naive cirrhotic and noncirrhotic patients with chronic hepatitis $C$ virus genotype 1, 4, or 6 infection: a randomized trial. Ann Int Med 2015;163:1-13.

26 Majumdar A, Kitson MT, Roberts SK: Systematic review: current concepts and challenges for the direct-acting antiviral era in hepatitis C cirrhosis. Aliment Pharmacol Ther 2016;43:1276-1292.

27 Di Marco V, Calvaruso V, Ferraro D, Bavetta MG, Cabibbo G, Conte E, Cammà C, Grimaudo S, Pipitone RM, Simone F, Peralta S, Arini A, Craxì A: Effects of viral eradication in patients with HCV and cirrhosis differ with stage of portal hypertension. Gastroenterology 2016, Epub ahead of print.

28 Deterding K, Schlevogt B, Port K, Cornberg M, Wedemeyer H: Letter: can persisting liver stiffness indicate increased risk of hepatocellular cell carcinoma after successful anti-HCV therapy? - authors' reply. Aliment Pharmacol Ther 2016;43:546-547.

29 Karlas T, Benckert J, Beer S, Keim V, Berg T, Wiegand J: Letter: can persisting liver stiffness indicate increased risk of hepatocellular cell carcinoma, after successful anti-HCV therapy? Aliment Pharmacol Ther 2016;43: 543-544.

-30 Harris RJ, Martin NK, Rand E, Mandal S, Mutimer D, Vickerman P, Ramsay ME, Angelis D de, Hickman M, Harris HE: New treatments for hepatitis C virus (HCV): scope for preventing liver disease and HCV transmission in England. J Viral Hepat 2016, Epub ahead of print.

-31 Ueno Y, Sollano JD, Farrell GC: Prevention of hepatocellular carcinoma complicating chronic hepatitis C. J Gastroenterol Hepatol 2009;24:531-536.

-32 Reig M, Mariño Z, Perelló C, Iñarrairaegui M, Ribeiro A, Lens S, Díaz A, Vilana R, Darnell A, Varela M, Sangro B, Calleja JL, Forns X, Bruix J: Unexpected early tumor recurrence in patients with hepatitis C virus-related hepatocellular carcinoma undergoing interferon-free therapy: a note of caution. J Hepatol 2016, Epub ahead of print.

-33 Schütte K, Bornschein J, Kahl S, Seidensticker R, Arend J, Ricke J, Malfertheiner P: Delayed diagnosis of HCC with chronic alcoholic liver disease. Liver Cancer 2012;1:257-266.

34 Schütte K, Kipper M, Kahl S, Bornschein J, Götze T, Adolf D, Arend J, Seidensticker R, Lippert H, Ricke J, Malfertheiner P: Clinical characteristics and time trends in etiology of hepatocellular cancer in Germany. Digestion 2013;87:147-159.

-35 Weinmann A, Koch S, Niederle IM, Schulze-Bergkamen H, König J, Hoppe-Lotichius M, Hansen T, Pitton MB, Düber C, Otto G, Schuchmann M, Galle PR, Wörns MA: Trends in epidemiology, treatment, and survival of hepatocellular carcinoma patients between 1998 and 2009: an analysis of 1,066 cases of a German HCC registry. J Clin Gastroenterol 2014;48:279-289.

-36 Dugum M, McCullough A: Diagnosis and management of alcoholic liver disease. J Clin Transl Hepatol 2015;3: 109-116.

-37 Mancebo A, González-Diéguez ML, Cadahía V, Varela M, Pérez R, Navascués CA, Sotorríos NG, Martínez M, Rodrigo L, Rodríguez M: Annual incidence of hepatocellular carcinoma among patients with alcoholic cirrhosis and identification of risk groups. Clin Gastroenterol Hepatol 2013;11:95-101.

-38 Heckley GA, Jarl J, Asamoah BO, G-Gerdtham U: How the risk of liver cancer changes after alcohol cessation: a review and meta-analysis of the current literature. BMC Cancer 2011;11:446.

-39 Testino G, Leone S, Borro P: Alcohol and hepatocellular carcinoma: a review and a point of view. World J Gastroenterol 2014;20:15943-15954.

40 Margini C, Dufour JF: The story of HCC in NAFLD: from epidemiology, across pathogenesis, to prevention and treatment. Liver Int 2016;36:317-324.

41 Ertle J, Dechêne A, Sowa J, Penndorf V, Herzer K, Kaiser G, Schlaak JF, Gerken G, Syn W, Canbay A: Non-alcoholic fatty liver disease progresses to hepatocellular carcinoma in the absence of apparent cirrhosis. Int J Cancer 2011;128:2436-2443.

42 Schütte K, Schulz C, Poranzke J, Antweiler K, Bornschein J, Bretschneider T, Arend J, Ricke J, Malfertheiner P: Characterization and prognosis of patients with hepatocellular carcinoma (HCC) in the non-cirrhotic liver. BMC Gastroenterol 2014;14:117.

-43 Hannah WN Jr, Harrison SA: Effect of weight loss, diet, exercise, and bariatric surgery on nonalcoholic fatty liver disease. Clin Liver Dis 2016;20:339-350. 
44 Vilar-Gomez E, Martinez-Perez Y, Calzadilla-Bertot L, Torres-Gonzalez A, Gra-Oramas B, Gonzalez-Fabian L, Friedman SL, Diago M, Romero-Gomez M: Weight loss through lifestyle modification significantly reduces features of nonalcoholic steatohepatitis. Gastroenterol 2015;149:367-378.e5; quiz e14-e15.

45 Hannah WN, Harrison SA: Lifestyle and dietary interventions in the management of nonalcoholic fatty liver disease. Dig Dis Sci 2016;61:1365-1374.

46 Sakai H, Shirakami Y, Shimizu M: Chemoprevention of obesity-related liver carcinogenesis by using pharmaceutical and nutraceutical agents. World J Gastroenterol 2016;22:394-406.

47 Shimizu M, Tanaka T, Moriwaki H: Obesity and hepatocellular carcinoma: targeting obesity-related inflammation for chemoprevention of liver carcinogenesis. Semin Immunopathol 2013;35:191-202.

48 Chen H, Shieh J, Chang C, Chen T, Lin J, Wu M, Lin J, Wu C: Metformin decreases hepatocellular carcinoma risk in a dose-dependent manner: population-based and in vitro studies. Gut 2013;62:606-615.

49 Li Y, Liu L, Wang B, Wang J, Chen D: Metformin in non-alcoholic fatty liver disease: a systematic review and meta-analysis. Biomed Rep 2013;1:57-64.

50 Singh S, Singh PP, Singh AG, Murad MH, Sanchez W: Anti-diabetic medications and the risk of hepatocellular cancer: a systematic review and meta-analysis. Am J Gastroenterol 2013;108:881-891; quiz 892.

51 Zhang H, Gao C, Fang L, Zhao H, Yao S: Metformin and reduced risk of hepatocellular carcinoma in diabetic patients: a meta-analysis. Scand J Gastroenterol 2013;48:78-87.

52 Singh S, Singh PP, Roberts LR, Sanchez W: Chemopreventive strategies in hepatocellular carcinoma. Nat Rev Gastroenterol Hepatol 2014;11:45-54.

53 Singh S, Singh PP, Singh AG, Murad MH, Sanchez W: Statins are associated with a reduced risk of hepatocellular cancer: a systematic review and meta-analysis. Gastroenterology 2013;144:323-332.

54 Morrison MC, Mulder P, Salic K, Verheij J, Liang W, van Duyvenvoorde W, Menke A, Kooistra T, Kleemann R, Wielinga PY: Intervention with a caspase-1 inhibitor reduces obesity-associated hyperinsulinemia, non-alcoholic steatohepatitis (NASH) and hepatic fibrosis in LDLR-/-.Leiden mice. Int J Obes (Lond) 2016, Epub ahead of print.

55 Barreyro FJ, Holod S, Finocchietto PV, Camino AM, Aquino JB, Avagnina A, Carreras MC, Poderoso JJ, Gores GJ: The pan-caspase inhibitor Emricasan (IDN-6556) decreases liver injury and fibrosis in a murine model of nonalcoholic steatohepatitis. Liver Int 2015;35:953-966.

-56 Neuschwander-Tetri BA, Loomba R, Sanyal AJ, Lavine JE, van Natta ML, Abdelmalek MF, Chalasani N, Dasarathy S, Diehl AM, Hameed B, Kowdley KV, McCullough A, Terrault N, Clark JM, Tonascia J, Brunt EM, Kleiner DE, Doo E: Farnesoid X nuclear receptor ligand obeticholic acid for non-cirrhotic, non-alcoholic steatohepatitis (FLINT): a multicentre, randomised, placebo-controlled trial. Lancet 2015;385:956-965.

57 Fan J, Farrell GC: Prevention of hepatocellular carcinoma in nonviral-related liver diseases. J Gastroenterol Hepatol 2009;24:712-719.

58 Kowdley KV: Iron, hemochromatosis, and hepatocellular carcinoma. Gastroenterology 2004;127(5 suppl 1):S79-S86.

59 Turner PC, Sylla A, Gong YY, Diallo MS, Sutcliffe AE, Hall AJ, Wild CP: Reduction in exposure to carcinogenic aflatoxins by postharvest intervention measures in west Africa: a community-based intervention study. Lancet 2005;365:1950-1956. 